\title{
CFD simulation of bubbling and collapsing characteristics in a gas-solid fluidized bed
}

\author{
Pei Pei ${ }^{1}$, Zhang Kai ${ }^{1 *}$, Lu Erwei ${ }^{1}$ and Wen Dongsheng ${ }^{2}$ \\ ${ }^{1}$ State Key Laboratory of Heavy Oil Processing, China University of Petroleum, Beijing 102249, China; \\ ${ }^{2}$ School of Engineering and Materials Science, Queen Mary University of London, Mile End Road, London, UK, E1 4NS
}

\begin{abstract}
Computational Fluid Dynamics (CFD) has become an alternative method to experiments for understanding the fluid dynamics of multiphase flow. A two-fluid model, which contains additional terms in both the gas- and solid-phase momentum equations, is used to investigate the fluidization quality in a fluidized bed. A case study for quartz sand with a density of $2,660 \mathrm{~kg} / \mathrm{m}^{3}$ and a diameter of $500 \mu \mathrm{m}$, whose physical property is similar to a new kind of catalyst for producing clean fuels through the residue fluid catalytic cracking process, is simulated in a two-dimensional fluidized bed with $0.57 \mathrm{~m}$ width and 1.00 $\mathrm{m}$ height. Transient bubbling and collapsing characteristics are numerically investigated in the platform of CFX 4.4 by integrating user-defined Fortran subroutines. The results show that the fluidization and collapse process is in fair agreement with the classical theory of Geldart B classification, but the collapse time is affected by bubbles at the interface between the dense phase and freeboard.
\end{abstract}

Key words: Fluidized bed, CFD simulation, bubbling and collapsing behaviors

\section{Introduction}

Heavy oil has become a main feedstock of refineries with decreasing production and rapidly rising price of conventional oils. In the meantime, the increasing problems about global warming, carbon emission and environment deterioration require more and more stringent environmental regulations for clean fuel production worldwide. Fluid catalytic cracking (FCC) plays a vital role in producing liquid fuels (gasoline, kerosene and middle distillates). Accordingly, a number of novel catalysts and processes for clean liquid fuels production, such as FCC naphtha olefin reduction, FCC naphtha aromatization, FCC naphtha desulfurization and C4-alkenes aromatization processes, have been developed (Cheng et al, 2002; Wang et al, 2002). One of them is to utilize excess heat generated by FCC to supply a new process using a special catalyst to produce clean gasoline (Gao et al, 2008). Different from the traditional FCC catalyst particles belonging to Geldart A classification (Geldart, 1973), the diameter of this type of special catalyst particle is above 300 $\mu \mathrm{m}$, which belongs to Geldart B classification. It is important to understand the fluidization behavior of this kind of catalyst particle to develop and optimize a new process for producing clean gasoline from heavy oil.

As an effective and simple method, the bed collapse technique has been regarded as a standard tool for predicting the fluidization quality and widely used to investigate the hydrodynamics of fluidized beds (Cherntongchai and Brandani, 2005). Many papers concerning this issue have been published, most of them, however, are based on

*Corresponding author. email: kaizhang@cup.edu.cn

Received August 28, 2008 experimental measurements (Geldart, 1986; Cherntongchai and Brandani, 2005; Gutfinger et al, 2005; Fu and Liu, 2007). In the past half century, Computational Fluid Dynamics (CFD) has become an emerging technique for investigating the hydrodynamic behavior of gas-solid fluidized beds as an alternative method to the step-by-step experimental scaleup. For instance, Gelderbloom et al (2003) simulated the bubbling and collapsing behavior in the gas-solid fluidized bed for Geldart A, B and C Group particles by using the Eulerian-Eulerian model based upon the granular kinetic theory. However, there is still no consensus about two important force items, the solid phase pressure and solid stress, in the solid momentum equations (Chen et al, 1999; Zhang et al, 2005). The objective of this work is to simulate the bubbling and collapsing characteristics of the new catalyst particle (Gao et al, 2008) in a gas-solid fluidized bed by using a simple two-fluid model proposed by Brandani and Zhang (2006).

\section{Mathematical model}

There are two kinds of mathematic models for describing the hydrodynamics in a gas-solid fluidized bed, i.e., EulerianLagrangian model and Eulerian-Eulerian model. The former considers the solid phase at a particle level, which is still too complicated to apply to an engineering installation at our present technical state (Knowlton et al, 2005). The latter model treats both gas and solid phases as interpenetrating continua, which largely reduce the computational time and provide useful design information (Zhang et al, 2005). However, the role and modelling of the solid phase pressure and solid stress in the solid momentum equations have been debated by many researchers (Chen et al, 1999; Zhang et al, 
2005). For instance, Foscolo and Gibilaro (1987) proposed a particle-bed model (PBM) to investigate fluid dynamic stability in one-dimensional fluidized beds. Chen et al (1999) extended it further to a two-dimensional formation that can predict qualitatively the fluidization quality in both gassolid and liquid-solid systems. It should be noted, though, that the classical PBM ignores the particle effect on the gas momentum balance. Recently, a model starting from the finite formulation of the two-fluid theory with consideration of the effect of the discrete nature of the particles has been proposed by Zhang et al (2005) and Brandani and Zhang (2006). The model includes two important features: the characteristic length is of the order of the particle diameter and only a correlation for drag force coefficient is needed to close the governing equations. A detailed derivation can be found in a paper by Brandani and Zhang (2006), and is briefly summarized here.

The continuity and momentum balance equations, describing gas and particle flows in the two-dimensional cold model of fluidized beds, are given below:

Continuity equations

Particle phase

$\frac{\partial \varepsilon_{\mathrm{P}}}{\partial t}+\nabla \cdot\left(\varepsilon_{\mathrm{P}} \vec{u}_{\mathrm{P}}\right)=0$

Gas phase

$$
\frac{\partial \varepsilon_{\mathrm{g}}}{\partial t}+\nabla \cdot\left(\varepsilon_{\mathrm{g}} \vec{u}_{\mathrm{g}}\right)=0
$$

Momentum equations

Particle phase

$$
\frac{\partial\left(\varepsilon_{\mathrm{p}} \rho_{\mathrm{p}} \vec{u}_{\mathrm{p}}\right)}{\partial t}+\nabla \cdot\left(\varepsilon_{\mathrm{p}} \rho_{\mathrm{p}} \vec{u}_{\mathrm{p}} \vec{u}_{\mathrm{p}}\right)=\vec{F}_{\mathrm{p}}
$$

Gas phase

$$
\frac{\partial\left(\varepsilon_{\mathrm{g}} \rho_{\mathrm{g}} \vec{u}_{\mathrm{g}}\right)}{\partial t}+\nabla \cdot\left(\varepsilon_{\mathrm{g}} \rho_{\mathrm{g}} \vec{u}_{\mathrm{g}} \vec{u}_{\mathrm{g}}\right)=\vec{F}_{\mathrm{g}}
$$

where $\varepsilon$ represents volume fraction $\left(\varepsilon_{\mathrm{g}}+\varepsilon_{\mathrm{p}}=1\right), \vec{F}$ is net force and $\rho$ is density. The subscripts $\mathrm{g}$ and $\mathrm{p}$ indicate gas and particle phases, respectively. According to the closure principles of governing equations, net primary forces, $\vec{F}_{\mathrm{p}}$ and, $\vec{F}_{\mathrm{g}}$ need to be derived from the above basic variables.

Particle-phase force in the vertical direction is

$$
\begin{aligned}
F_{\mathrm{p} z}= & C_{D} \frac{3 \varepsilon_{\mathrm{p}} \rho_{\mathrm{g}}\left(u_{\mathrm{g}}-u_{\mathrm{p}}\right)\left(\vec{u}_{\mathrm{g}}-\vec{u}_{\mathrm{p}}\right) \mid}{4 d_{\mathrm{p}}} \varepsilon_{\mathrm{g}}^{-1.8}-\varepsilon_{\mathrm{p}} \rho_{\mathrm{p}} g \\
& -\varepsilon_{\mathrm{p}} \frac{\partial p}{\partial z}-d_{\mathrm{p}}\left[2 \varepsilon_{\mathrm{p}} \rho_{\mathrm{p}}+\left(1-2 \varepsilon_{\mathrm{p}}\right) \rho_{\mathrm{g}}\right] g \frac{\partial \varepsilon_{\mathrm{p}}}{\partial z}
\end{aligned}
$$

Particle-phase force in the lateral direction is

$$
F_{\mathrm{px}}=C_{D} \frac{3 \varepsilon_{\mathrm{p}} \rho_{\mathrm{g}}\left(v_{\mathrm{g}}-v_{\mathrm{p}}\right)\left|\left(\vec{u}_{\mathrm{g}}-\vec{u}_{\mathrm{p}}\right)\right|}{4 d_{\mathrm{p}}} \varepsilon_{\mathrm{g}}^{-1.8}-\varepsilon_{\mathrm{p}} \frac{\partial p}{\partial x}
$$

Gas-phase force in the vertical direction is

$$
\begin{aligned}
F_{\mathrm{g} z}= & -C_{D} \frac{3 \varepsilon_{\mathrm{p}} \rho_{\mathrm{g}}\left(u_{\mathrm{g}}-u_{\mathrm{p}}\right)\left|\left(\vec{u}_{\mathrm{g}}-\vec{u}_{\mathrm{p}}\right)\right|}{4 d_{\mathrm{p}}} \varepsilon_{\mathrm{g}}^{-1.8}-\varepsilon_{\mathrm{g}} \rho_{\mathrm{g}} \mathrm{g} \\
& -\varepsilon_{\mathrm{g}} \frac{\partial p}{\partial z}-d_{\mathrm{p}}\left[2 \varepsilon_{\mathrm{g}} \rho_{\mathrm{g}}+\left(1-2 \varepsilon_{\mathrm{g}}\right) \rho_{\mathrm{p}}\right] \mathrm{g} \frac{\partial \varepsilon_{\mathrm{g}}}{\partial z}
\end{aligned}
$$

Gas-phase force in the lateral direction is

$$
F_{\mathrm{gx}}=-C_{D} \frac{3 \varepsilon_{\mathrm{p}} \rho_{\mathrm{g}}\left(v_{\mathrm{g}}-v_{\mathrm{p}}\right)\left|\left(\vec{u}_{\mathrm{g}}-\vec{u}_{\mathrm{p}}\right)\right|}{4 d_{\mathrm{p}}} \varepsilon_{\mathrm{g}}^{-1.8}-\varepsilon_{\mathrm{g}} \frac{\partial p}{\partial x}
$$

The terms on the right-hand sides of Eqs. 5 and 7 are the inter-phase drag, gravity, pressure drop, and the additional forces, respectively.

The empirical Dallavalle relation is used to express drag coefficient $\mathrm{CD}$ as below:

$$
C_{D}=\left(0.63+\frac{4.8}{\sqrt{\mathrm{Re}}}\right)^{2}
$$

where

$$
\operatorname{Re}=\frac{\varepsilon_{\mathrm{g}} \rho_{\mathrm{g}}\left|\vec{u}_{\mathrm{g}}-\vec{u}_{\mathrm{p}}\right| d_{\mathrm{p}}}{\mu_{\mathrm{g}}}
$$

\section{Numerical simulation}

Simulation is carried out in a two-dimensional fluidized bed with a height of $1.00 \mathrm{~m}$ and a width of $0.57 \mathrm{~m}$. The fluidizing gas is air and the particle phase is quartz sand, whose physical properties are listed in Table 1. Initially, the gas velocity in the vertical direction is the minimum fluidization velocity, whilst the gas velocity in the lateral direction and the particle velocity vector are zero. The static bed height is set as $0.50 \mathrm{~m}$ and the pressure profile in the whole bed is calculated by the hydrostatic bed height. The uniform staggered grid method is used in the computing process, and the total number of grids is $80 \times 76$. Here, 80 and 76 are in the vertical and lateral directions, respectively. The time step is $10-4 \mathrm{~s}$ during the computational procedure. The boundary conditions are set as below:

(1) The Dirichlet boundary is used at the bottom of the bed. Twice the minimal fluidization velocity is set for the bubbling state, whilst zero for the collapsing state.

Table 1 Physical properties of the gas-solid system

\begin{tabular}{ccc}
\hline & Gas phase & Particle phase \\
\hline Density, $\mathrm{kg} / \mathrm{m}^{3}$ & 1.21 & 2660 \\
Viscosity, Pa·s & $1.81 \times 10^{-5}$ & - \\
Diameter, $\mu \mathrm{m}$ & - & 500 \\
$\begin{array}{c}\text { Minimum fluidization velocity, } \\
\mathrm{m} / \mathrm{s}\end{array}$ & - & 0.25 \\
Minimum fluidization voidage & - & 0.402 \\
\hline
\end{tabular}


(2) Pressure boundary is used at the top of the freeboard.

(3) The lateral walls are treated as the no slip boundary conditions for both gas and particle phases.

A commercial CFD code, CFX4.4, is used to solve the governing equations. In the momentum equations, the interphase drag and particle-phase elasticity force terms are calculated through user-defined Fortran subroutines, and the other items are obtained directly by using command file. Each term in the governing equations is discretized in space by using the second-order centred difference apart from the advection terms. As a default option of CFX 4.4, a fully implicit backward difference time stepping procedure is implemented. Different difference methods are used to treat the advection terms: central difference scheme for gas or solid volume fraction, upwind difference scheme for the shared pressure field, and hybrid difference scheme for all velocity components. A modified version of SIMPLE (semiimplicit method for pressure-linked equations) algorithm is implemented to deal with the velocity-pressure coupling.

Difficulties needed to be overcome to prevent the maximum particle concentration exceeding the fixed-bed value for randomly packed spheres. Gidaspow and Ettehadleh (1982), Kuipers et al (1992), and Zhang et al (2002) added a pressure term in the particle-phase momentum equations. According to Gidaspow's statement (Gidaspow, 1986), this term becomes numerical significance only when the void fraction is below the minimum fluidization void fraction. It also helps to make the system numerically stable, because it converts the imaginary characteristics into real values. For some calculations, it is necessary to adjust this stress term to prevent the void fraction from reaching impossibly low values. However, Massoudi et al (1992) compared nine empirical relations for the modulus of elasticity, and found orders of magnitude differences. It is clear that the solidphase pressure is an empirical modification that depends strongly upon the gas-solid system. Alternatively, the approach proposed by Chen et al (1999) was used to adjust the particle pressure in each grid according to the particleparticle contact forces, which is based on a point relaxation technique without linearization. Because this method cannot be employed directly in CFX 4.4, a similar technique was proposed by Zhang et al (2005) and Brandani and Zhang (2006), which is to rebuild excess solid concentration together with a correction to the corresponding momentum equations.

\section{Classical description of bed collapse}

When the gas supplied to a fluidized bed is switched off, the bed starts to collapse and eventually achieves a fixed bed. As shown schematically in Fig.1, the variation of the surface of the dense phase with time is generally divided into three stages, i.e. (1) bubble escape stage: all bubbles in the bed ascend and escape the dense phase; (2) hindered sedimentation stage: gas in the emulsion phase passes through the bed and enters the freeboard; and (3) solids consolidation stage. Settled zone starts to form in the bottom of the bed when bubble or interstitial gas goes up within the bed. Accordingly, the transitional point between the hindered sedimentation stage and the solids consolidation stage is when the surface of the bed reaches the interface of the settled zone. During the solids consolidation stage, there exists a slow compaction, depending on the particle characteristics (Yang et al, 1985). This phenomenon characterizes the bed collapse process for Geldart Group A powders. On the other hand, bed collapse is very fast for Group B powders in Fig. 2 (Geldart, 1986) since inter-forces among particles are negligible and bubbles start to form at or only slightly above minimum fluidization velocity.

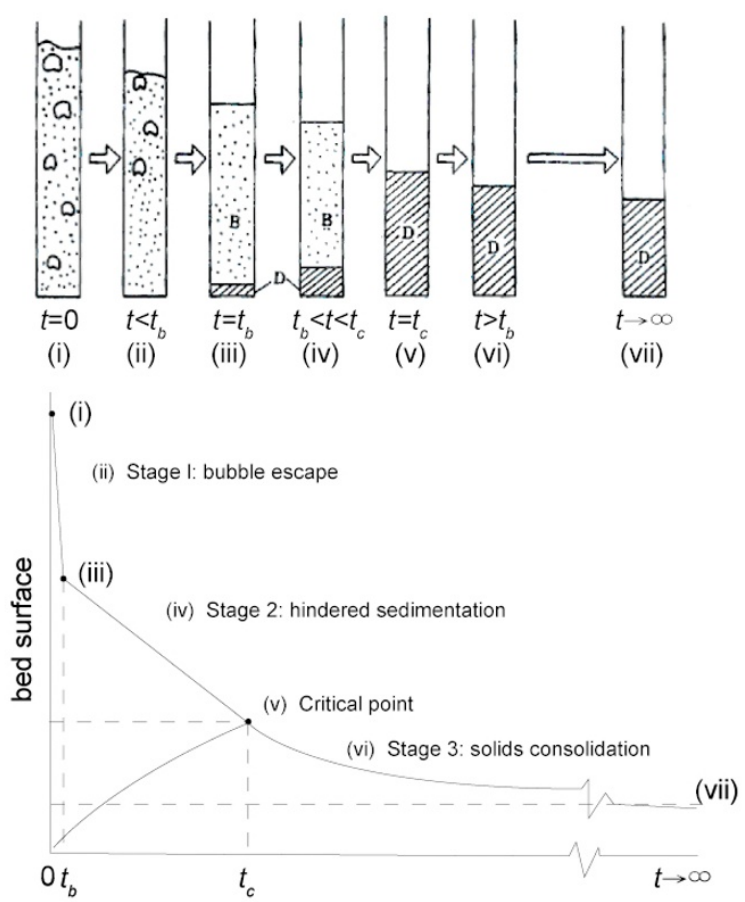

Fig. 1 Modeling of the three-stage of bed collapsing process (Yang et al, 1985)

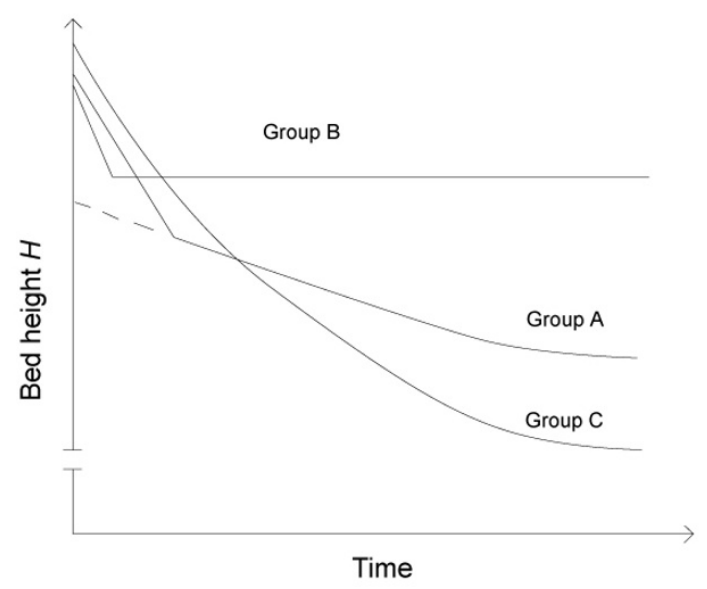

Fig. 2 Bed collapsing process curves for Group A, B and C powders (Geldart, 1986)

\section{Results and discussion}

\subsection{Bubbling state}

When a fluidized bed operates in the bubbling state, 
the dense-phase regime consists of the emulsion phase and bubbles. Fig. 3 presents a series of snapshots of solid volume fraction in the bed. At the time $t=0 \mathrm{~s}$, the inlet gas velocity abruptly switches to twice the minimum fluidization velocity $(0.5 \mathrm{~m} / \mathrm{s})$ from the minimum fluidization velocity $(0.25 \mathrm{~m} / \mathrm{s})$. The surface of the dense phase rises rapidly at $t<1.0 \mathrm{~s}$, and begins to descend abruptly once bubbles escape from the dense phase.

The average height of the dense phase has been considered as an important macroscopic indicator of the fluid dynamic behaviour in the bubbling fluidized bed. To calculate the average height of the dense phase, the boundary between the dense phase and freeboard is defined as the contour line of solid volume fraction as 0.20 in this study, which is the same as that simulated jet boundary by Gidaspow and Ettehadleh (1982) and Zhang et al $(2002 ; 2003)$. It can be found that the surface of the dense phase expands linearly before bubbles reach the top of the dense phase, and then declines after these bubbles detach from the dense phase in the beginning stage $(t<1.5 \mathrm{~s})$ in Fig. $4 \mathrm{a}$. When time is longer than $1.5 \mathrm{~s}$, the surface exhibits fluctuation characteristics in nature (Fig. 4b). From Fig. 4, it is easy to find that the whole bubbling process can be divided into the start-up and quasi-steady fluidization stages when inlet gas velocity is greater than its initial fluidization velocity $(0.25 \mathrm{~m} / \mathrm{s})$. This reveals that the bed collapse must start from the quasi-steady fluidization stage.

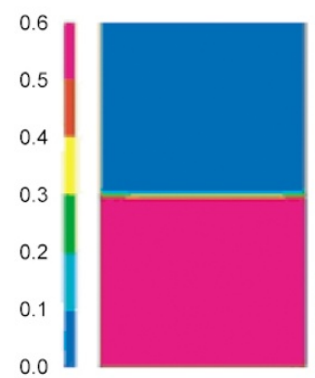

$t=0.0 \mathrm{~s}$

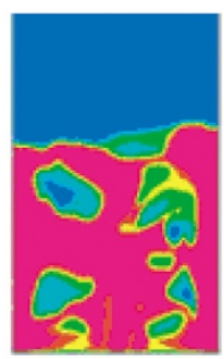

$2.0 \mathrm{~s}$

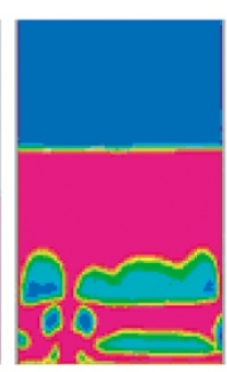

$0.5 \mathrm{~s}$

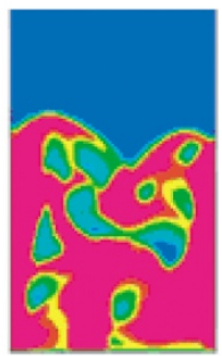

$3.0 \mathrm{~s}$

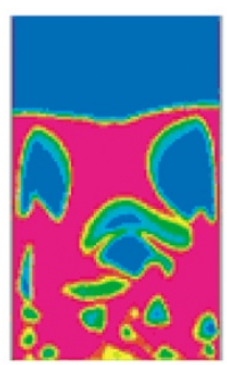

$0.9 \mathrm{~s}$

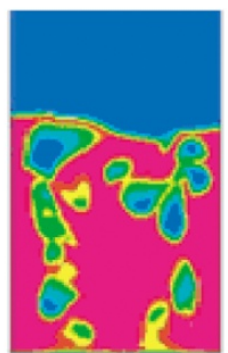

$5.0 \mathrm{~s}$

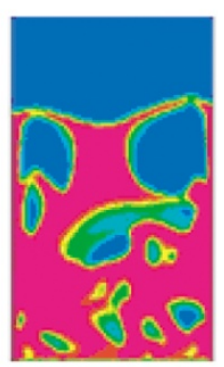

$1.0 \mathrm{~s}$

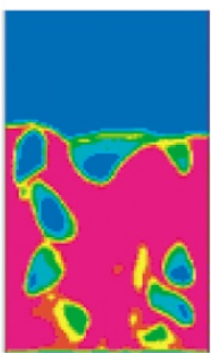

$8.5 \mathrm{~s}$

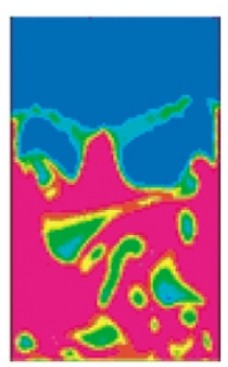

$1.1 \mathrm{~s}$

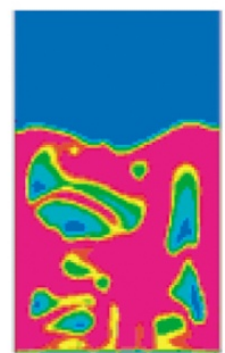

$9.0 \mathrm{~s}$

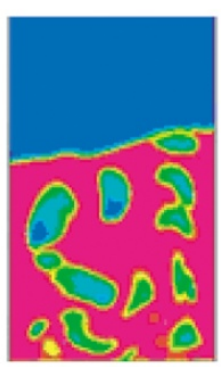

$1.5 \mathrm{~s}$

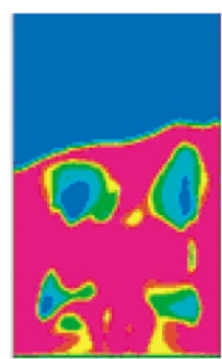

$1.5 \mathrm{~s}$

Fig. 3 Snapshots of solid volume fraction in the bubbling state

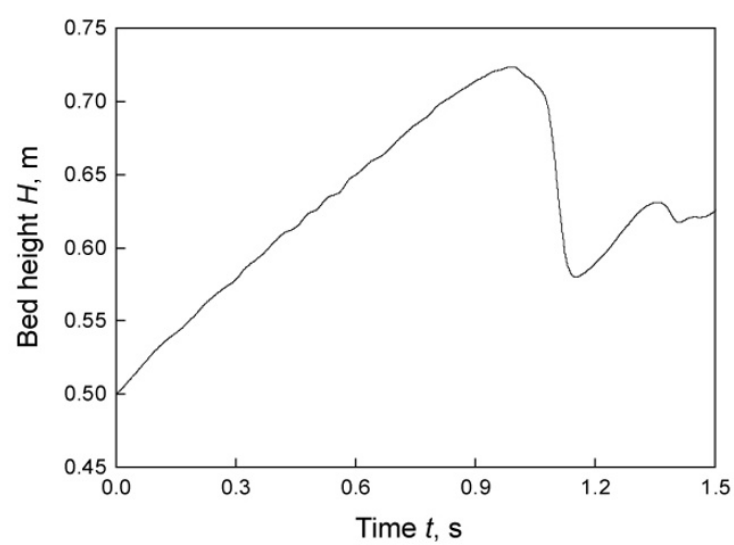

(a) In the beginning stage $(t<1.5 \mathrm{~s})$

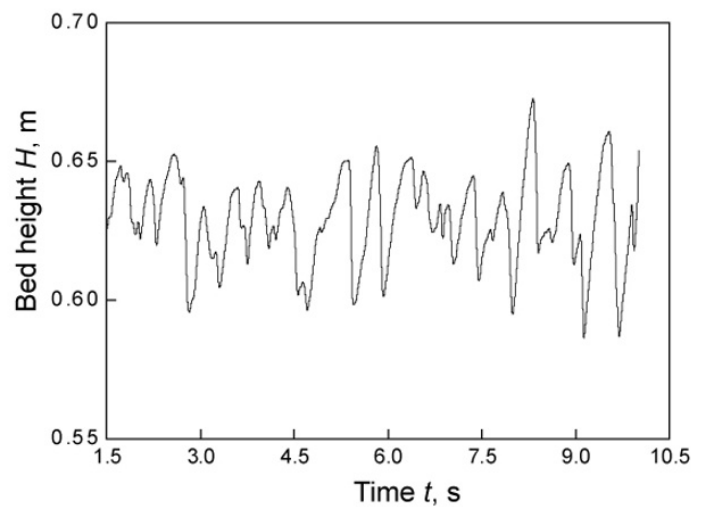

(b) After $1.5 \mathrm{~s}$

Fig. 4 Average bed height as a function of time in the bubbling state 


\subsection{Computational bed collapse}

As mentioned above, the collapsing process should start after the quasi-steady fluidization stage. To understand the effect of dynamic bubbles on bed collapse, Figs. 5-7 show the instantaneous bed collapsing processes and their collapse curves when gas supply is shut off at $t=5.0,8.5$ and $10.0 \mathrm{~s}$, respectively. The color code for solid volume fraction is the same as that in Fig. 3.

At $t=5.0 \mathrm{~s}$, no bubble exists at the interface between the dense phase and freeboard (Fig. 5a) and the bed height is about $0.640 \mathrm{~m}$ (Fig. 5b). The bed begins to rise slightly when bubble erupts at $t=5.02 \mathrm{~s}$. Then the interface declines linearly because both bubbles and interstitial gas go up in the emulsion phase and enter quickly into the freeboard. After $0.27 \mathrm{~s}$, a 0.49 mhigh fixed bed comes into view, which is slightly lower than the 0.50 mhigh initial bed in the minimum fluidization state. At $t=8.5 \mathrm{~s}$, there is a bubble at the interface between the dense phase and freeboard (Fig. 6a) and the

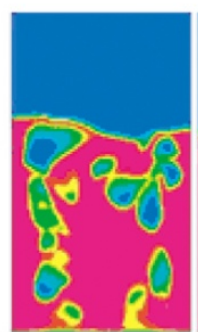

$t=5.0 \mathrm{~s}$

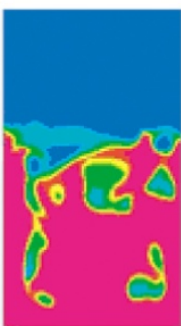

$5.1 \mathrm{~s}$

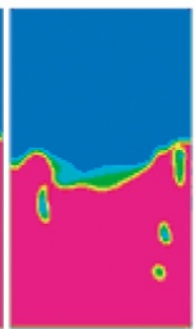

$5.2 \mathrm{~s}$

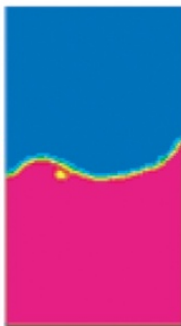

$5.3 \mathrm{~s}$

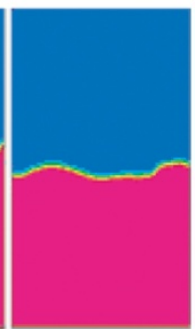

$5.4 \mathrm{~s}$

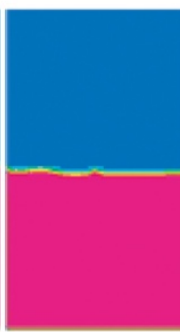

$6.0 \mathrm{~s}$

(a) Snapshots of the bed collapse process

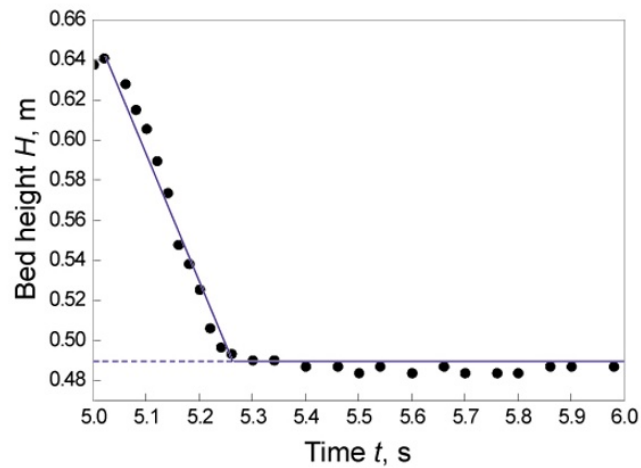

(b) Bed collapse curve

Fig. 5 Bed collapse process when gas supply is shut off at $t=5.0 \mathrm{~s}$

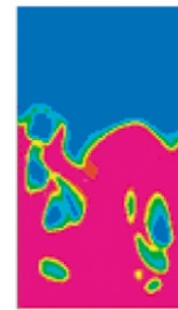

$t=8.5 \mathrm{~s}$

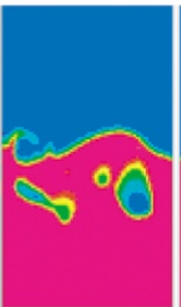

$8.6 \mathrm{~s}$

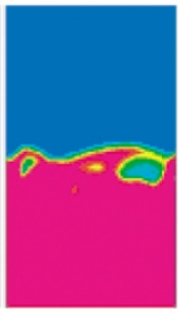

$8.7 \mathrm{~s}$

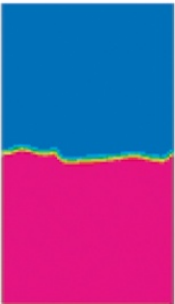

$8.8 \mathrm{~s}$

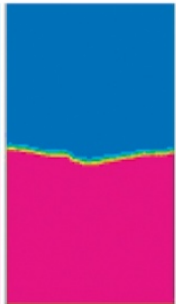

$8.9 \mathrm{~s}$

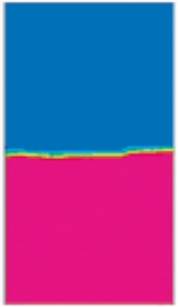

$9.4 \mathrm{~s}$

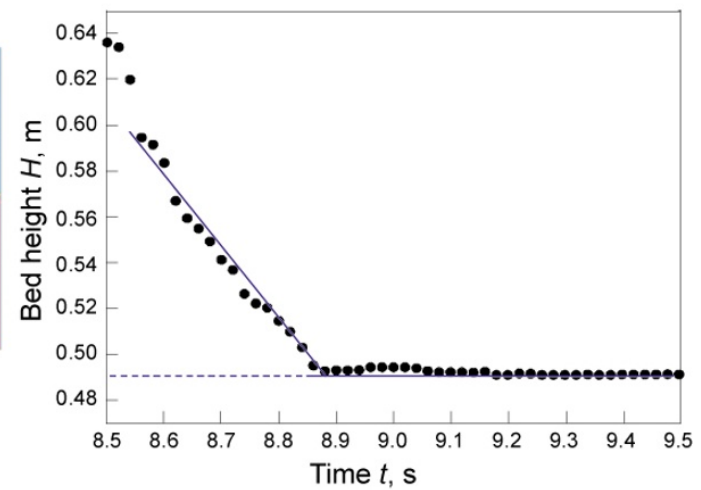

(a) Snapshots of the bed collapse process

Fig. 6 Bed collapse process when gas supply is shut off at $t=8.5 \mathrm{~s}$

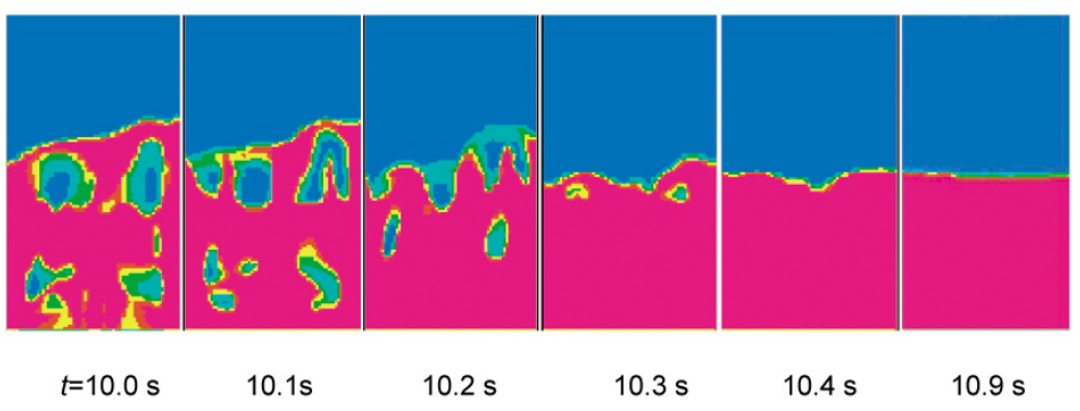

(a) Snapshots of the bed collapse process

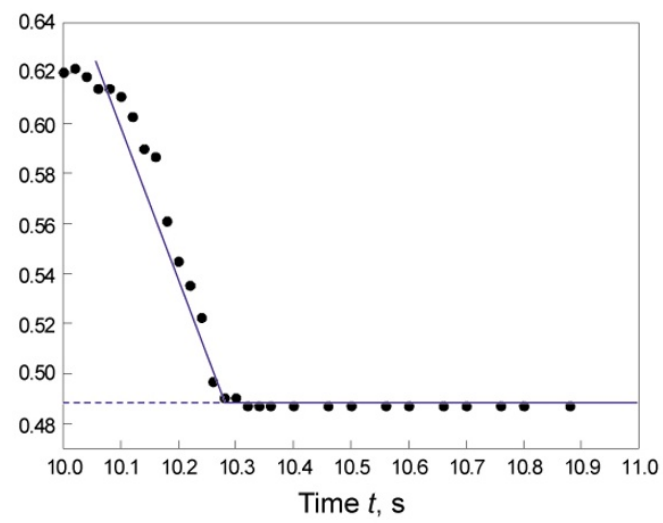

(b) Bed collapse curve

Fig. 7 Bed collapse process when gas supply is shut off at $t=10.0 \mathrm{~s}$ 
bed height is about $0.636 \mathrm{~m}$ (Fig. 6b). The interface starts to decline directly without a small raise in the beginning stage, which is different from that in Fig. 5b. After 0.37 s, however, the final bed height is still $0.49 \mathrm{~m}$. Similar to the bed collapse at $t=5.0 \mathrm{~s}$, there is no bubble at the interface between the dense phase and freeboard at $t=10.0 \mathrm{~s}$ (Fig. 7a). Although the initial bed height $(\sim 0.620 \mathrm{~m})$ is lower than that in Fig. $5 \mathrm{a}$, the final bed height decreases to $0.49 \mathrm{~m}$ at $t=10.27 \mathrm{~s}$ (Fig. $7 \mathrm{~b}$ ).

It is clear that the bed surface declines first and eventually reaches a non-fluidized (or fixed-bed) state in the form of loose packing as shown in Figs. 5a, 6a and 7a. However, slight differences can be found when the gas is switched off at different times as shown in Fig. 8. Although the initial bed height varies, the same collapse time is obtained when the gas is turned off at $t=5.0 \mathrm{~s}$ and $10.0 \mathrm{~s}$. This is mainly because that all bubbles are within the dense-phase region. On the other hand, a relatively long collapse time was necessary when the gas is turned off at $t=8.5 \mathrm{~s}$ since a bubble is erupting from the interface.

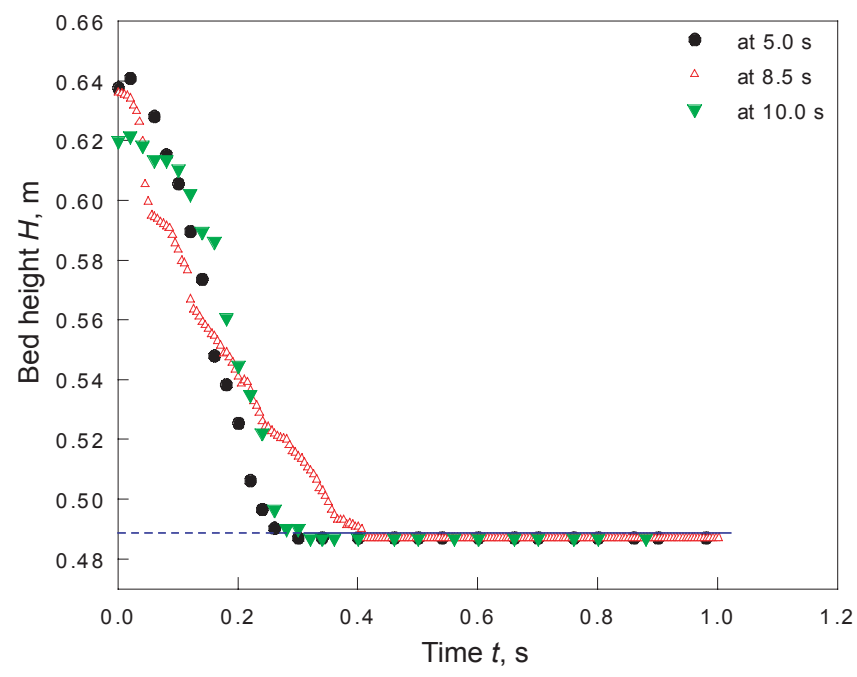

Fig. 8 Bed surface collapse curves when gas is shut off at different times

\section{Conclusions}

The fluidization quality of quartz sand is investigated numerically in a fluidized bed by using the two-fluid model proposed by Brandani and Zhang (2006) in order to simulate the hydrodynamic behavior of a new kind of catalyst for clean fuels production. Main conclusions from the simulation are summarized as below:

1) In the bubbling stage, the surface of the dense phase rises linearly as the inlet gas velocity is increased to twice the minimum fluidization velocity, and descends as bubbles escape from the dense phase, and reaches finally a quasisteady fluidization stage, with fluctuation feature in nature.

2) Different to the conventional three-stage model of FCC particles, the collapsing process of this type of catalytic particles includes only two stages, bubble escape and solids consolidation, a typical behaviour associated with the Geldart B classification.

3) The CFD modelling reveals clearly the effect of bubbles at the interface between the dense phase and freeboard on the collapse time, which is difficult to observe in experiments and should be taken into consideration in the modeling.

\section{Nomenclatures}

CD particle drag force coefficient

$d \mathrm{p}$ particle diameter, $\mathrm{m}$

$\vec{F}$ net force, $\mathrm{N} / \mathrm{m}^{3}$

$g$ acceleration due to gravity, $\mathrm{m} / \mathrm{s}^{2}$

$H$ bed height, $\mathrm{m}$

Re Reynolds number

$t$ time, s

$t \mathrm{~b}$ bubbles escape time, $\mathrm{s}$

$t c$ critical time, $\mathrm{s}$

$\vec{u} \quad$ velocity vector, $\mathrm{m} / \mathrm{s}$

$v$ velocity in lateral direction

$x$ lateral distance, $\mathrm{m}$

$z \quad$ vertical distance, $m$

Greek letters

$\varepsilon \quad$ volume fraction

$\rho$ density, $\mathrm{kg} / \mathrm{m}^{3}$

$\mu$ viscosity, $\mathrm{Ns} / \mathrm{m}^{2}$

Subscripts

g-gas

$\mathrm{p}$-particle

$\mathrm{x}$-lateral direction

$\mathrm{z}$ - vertical direction

\section{Acknowledgements}

Financial support from the Major State Basic Research Development Program of China (973 Program, 2005CB221205) and National Natural Science Foundation of China (No. 20490200 and 20576076) is gratefully acknowledged.

\section{References}

Brandani S and Zhang K. A new model for the prediction of the behaviour of fluidized beds. Powder Technology. 2006.163 (1-2): 80-87

Chen Z M, Gibilaro L G and Foscolo P U. Two-dimensional voidage waves in fluidized beds. Ind. Eng. Chem. Res. 1999. 58(3): 610-620

Cheng Z L, Chao, Z S, Wan H L, et al. Aromatization of mixed C4 hydrocarbons over ZnNi/HZSM-5 catalyst. Acta Petrolei Sinica. 2002.18(1): 24-30 (in Chinese)

Cherntongchai P and Brandani S. A model for the interpretation of the bed collapse experiment. Powder Technology. 2005. 151(1-3): $37-43$

Foscolo P U and Gibilaro L G. Fluid dynamic stability of fluidized suspension: the particle bed model. Chem. Eng. Sci. 1987.42(6): $1489-1500$

Fu Y F and Liu D Y. Novel experimental phenomena of fine-particle fluidized beds. Experimental Thermal and Fluid Science. 2007. 32(1): 341-344

Gao J S, Chang J, Lu C X, et al. Experimental and computational studies on flow behavior of gas-solid fluidized bed with disparately sized binary particles. Particuology. 2008. 6(2): 59-71

Geldart D. Gas Fluidization Technology. UK: University of Bradford. 1986. 36-37

Geldart D. Types of gas fluidization. Powder Technology. 1973. 285-292 
Gelderbloom S J, Gidaspow D and Lyczkowski R W. CFD simulations of bubbling/collapsing fluidized beds for three Geldart groups. AIChE. J. 2003. 49(4): 844-858

Gidaspow D and Ettehadleh B. Fluidization in two-dimensional beds with a jet. 2. Hydrodynamic modeling. I\&EC Fundam. 1982. 22(2): 193-201

Gidaspow D. Hydrodynamics of fluidization and heat transfer: supercomputer modeling. Appl Mech Rev. 1986. 39(1): 1-23

Gutfinger C, Goldshtein A and Weinstein H. A model for the collapse of a fluidized bed. Advanced Powder Technology. 2005. 16(1): 49-59

Knowlton T M, Karri S B R and Issangya A. Scale-up of fluidized-bed hydrodynamics. Powder Technology. 2005. 150 (2): 72-77

Kuipers J A M, Tammes H, Prins W, et al. Experimental and theoretical porosity profiles in two-dimensional gas-fluidized bed with a central jet. Powder Tech. 1992. 71(1): 87-99

Massoudi M, Rajagopal K R, Ekmann J M, et al. Remarks on the modeling of fluidized systems. AIChE. J. 1992. 38(3): 471-472

Wang S Y, Chen X G and Xu C M. Study on catalytic pyrolysis of C4 mixture. Petroleum Processing and Petrochemicals. 2002. 33(12): 54-57 (in Chinese)

Yang Z, Tung Y and Kwuak M. Characterizing fluidization by bed collapsing method. Chem. Eng. Commun. 1985. 39(1-6): 217-232

Zhang K, Brandani S and Bi J C. Computational fluid dynamics for dense gas-solid fluidized beds. Progress in Natural Science. 2005. Special Issue: $42-51$

Zhang K, Zhang H, Lovick J, et al. Numerical computation and experimental verification of the jet region in a fluid bed, Ind. Eng. Chem. Research. 2002. 41(15): 3696-3704

Zhang K, Zhang J Y and Zhang B J. Hydrodynamic model in a gas fluidized bed with binary particle. Powder Technology. 2003. 132(1):30-38

(Edited by Zhu Xiuqin) 